\title{
Determination of the Relationship between the Body Composition and Pulmonary Function in Obese Individuals
}

\author{
Derya Güzel ${ }^{1}$, Yusuf Aydemir², Ramazan Akdemir ${ }^{3}$, Ünal Erkorkmaz
}

${ }^{1}$ Department of Physiology, Sakarya University School of Medicine, Sakarya, Turkey

${ }^{2}$ Department of Chest Diseases, Sakarya University School of Medicine, Sakarya, Turkey

${ }^{3}$ Department of Cardiology, Sakarya University School of Medicine, Sakarya, Turkey

${ }^{4}$ Department of Biostatistics, Sakarya University School of Medicine, Sakarya, Turkey

\begin{abstract}
Objective: Body mass index (BMI) is used as a basic parameter in assessing obesity. However, BMI is not sensitive in the assessment of body fat percentage (BFP) and body fat distribution (BFD). The aim of this study is to determine the effect of BFP and BFD on the pulmonary functions and compare this effect with BMI.
\end{abstract}

Methods: This study was conducted with a total of 170 volunteers. BMI, waist-to-hip ratio (WHR), and BFPs of healthy normal weight, overweight, and obese individuals were measured and their pulmonary function tests were statistically compared with each other.

Results: There was no significant relationship between BMI increase and pulmonary function test results of the individuals. There were significant correlations between BFP increase and forced expiratory volume (FEV $\%$ ) and forced expiratory flow between $25 \%$ and $75 \%$ of $\mathrm{FVC}$ (FEF25-75\%). In the male patients, FEV \% value was negatively correlated with waist circumference. In female patients, WHR was positively correlated with $\mathrm{FEV}_{1} /$ forced vital capacity (FVC), $\mathrm{FEV}_{1} / \mathrm{FVC} \%$, whereas it was negatively correlated with $\mathrm{FEV}_{1} \%$ values.

Conclusion: Because the widely used BMI is incapable of distinguishing BFP and BFD, it can be insufficient for evaluating the lung functions.Therefore, determining the body composition is important in the evaluation of obese individuals.

Keywords: Body fat distribution, body mass index, lung function, pulmonary function test

\section{INTRODUCTION}

According to the World Health Organization (WHO), obesity is defined as "abnormal or excessive fat storage that can be risky for health". Obesity is a major public health problem with an increasing prevalence as a result of changing eating habits and sedentary lifestyle all over the world (1). Obesity has high mortality and morbidity rates due to its negative effects on all the system of the human body, including the respiratory system (2).WHO defines body mass index (BMI) as the basic parameter in assessing obesity (3). However, BMl is not sensitive in the assessment of body fat percentage (BFP) and body fat distribution (BFD) and it does not give a clear answer about whether the rise in body mass is due to adiposity or muscle mass increase (4). Therefore, determination of BFP by bio-impedance method and BFD by anthropometric measurements can better assess functional impairment (5).

In the majority of studies investigating the effects of obesity on the pulmonary functions, classification was performed with BMI. In a few studies conducted with anthropometric assessment and BFD, a negative correlation was found between pulmonary functions and visceral adiposity. In addition, the values of forced expiratory volume (FEV 1 ) and forced vital capacity (FVC) have shown to be reduced in proportion with lipoidosis (6).

The aim of this study was to determine the effect of BFP and BFD on the pulmonary functions of individuals who donot have any disorders that disrupt their pulmonary functions and to compare this effect with BMI. 


\section{METHODS}

This study was conducted with volunteers from Sakarya University Faculty of Medicine by receiving their informed consent. Detailed history was taken from all participants, and those with any known history of exposure to occupational or environmental factors that can affect the respiratory system were not included in the study. After detailed physical examination performed by pulmonology and cardiology specialists, some of the participants that were determined to have concomitant diseases affecting the respiratory system were excluded from the study. The remaining 170 healthy individuals were included in the study.

Individuals with BMI 18.5-24.9 were considered as normal, whereas those with $\mathrm{BMI} 25-29.9$ were overweight and those with $\mathrm{BMI} \geq 30$ were considered as obese. BFP was determined by the bioelectrical impedance method (TBF- $300^{\circledR}$ device; Tanita, Illinois, USA). Body fat mass (BFM) and BFP was calculated. Groups were classified using $95 \%$ percentile value of the normal value (BFM, \%, ideal=man $<28.8$ and wom-

Table 1. General characteristics of the patients

\begin{tabular}{|l|c|c|c|}
\hline General Characteristics $(\mathrm{n}=170)$ & Min. & Max. & $($ mean \pm SD) \\
\hline Age & 19 & 70 & $40.2 \pm 10.7$ \\
Waist circumference $(\mathrm{cm})$ & 69 & 150 & $101.8 \pm 14.7$ \\
Hip circumference $(\mathrm{cm})$ & 91 & 150 & $113.4 \pm 11.7$ \\
Height $(\mathrm{cm})$ & 150 & 198 & $169.5 \pm 8.8$ \\
Weight $(\mathrm{kg})$ & 45.8 & 130.6 & $81.8 \pm 17.2$ \\
BMI $\left(\mathrm{kg} / \mathrm{m}^{2}\right)$ & 16.9 & 43.1 & $28.4 \pm 5.2$ \\
BFP $(\%)$ & 11.1 & 48.5 & $28.7 \pm 7.9$ \\
BFM $(\mathrm{kg})$ & 5.9 & 55.4 & $23.9 \pm 9.5$ \\
FFM $(\mathrm{kg})$ & 39.0 & 82.0 & $57.9 \pm 12.0$ \\
\hline
\end{tabular}

BFM: Body fat mass; BFP: body fat percentage; BMI: body mass index; FFM: fat-free mass; Max.: maximum; Min.: minimum; SD: standard deviation an $<33.4$; high=man $\geq 28.8$ and woman $\geq 33.4$; BFM, $\mathrm{kg}$, ideal=man $<24.5 \mathrm{~kg}$ and woman $<23.5$, high=man $\geq 24.5$ and woman $\geq 23.5)(7)$. In the anthropometric measurements of the study group, the hip circumference was measured by taking the largest diameter on trochanter major and mid-waist circumference $(\mathrm{cm})$ between the lowest ribs and the iliac crest. The waist-to-hip ratio (WHR) was obtained by dividing the waist circumference to the hip circumference (8).

Pulmonary function tests (PFTs) were performed in accordance with the American Thoracic Society (ATS) criteria using a pulmonary function analyzer (ZAN Meßgreräte $\mathrm{GmbH}$, Oberthulba, Germany) (9). Individuals were informed before the measurements. Test was performed in a comfortable sitting position followed by $15 \mathrm{~min}$ of resting. A mouthpiece was placed between the teeth and lips. Then, a strong expiration was performed by the patient followed by a deep inspiration after breathing 3 times in a relaxed way. The test was repeated 3 times to get the best values. FVC, $\mathrm{FEV}_{1}, \mathrm{FEV}_{1} / \mathrm{FVC}$, forced expiratory flow between $25 \%$ and $75 \%$ of FVC (FEF25-75), FVC \% (expected), FEV $\%$ (expected), FEV $/$ /FVC\% (expected), and FEF25-75\% (expected) were also measured.

Ethics committee approval was received for this study from the ethics committee of Sakarya University Medical Faculty.

\section{Statistical Analysis \\ Kolmogorov-Smirnov test was used to evaluate whether the distri- bution of variables were normal. Accordingly, it was observed that all variables displayed a normal distribution. Two independent sam- ple t-test were used to compare the results of PFTs between the two groups. One-way analysis of variance (ANOVA) was used for the com- parison of parametric data among three BMI groups. Because there was a significant difference for age and gender of patient among/be- tween groups and age- or/and gender-adjusted parameters of PFTs, comparisons were evaluated by an analysis of covariance (ANCOVA) and Hotelling T2 test. For post-hoc multiple comparison of ANCOVA, bonferroni test was used. Relationships between variables were ex- amined using Pearson's correlation coefficients (partial correlation coefficients were calculated for age-adjusted correlations between}

Table 2. The comparisons of pulmonary functions and other characteristics among BMI groups

\begin{tabular}{|c|c|c|c|c|c|}
\hline PFTs & $\begin{array}{c}\text { Normal BMI }<24.9 \\
(n=46)\end{array}$ & $\begin{array}{c}\text { Overweight } \\
\text { BMI 25-29.9 }(n=61)\end{array}$ & $\begin{array}{c}\text { Obese } \\
\text { BMI } \geq 30(n=63)\end{array}$ & $\begin{array}{l}\text { Unadjusted } \\
\text { p values }\end{array}$ & $\begin{array}{l}\text { Age- and gender } \\
\text {-adjusted } p \text { values }\end{array}$ \\
\hline Age & $35.07 \pm 9.68$ & $40.9 \pm 10.01$ & $43.27 \pm 10.75$ & $<0.001$ & - \\
\hline Sex-male- (\%) & $14(30.4)$ & $41(67.2)$ & $38(60.3)$ & $<0.001$ & - \\
\hline $\mathrm{FEV}_{1}(\mathrm{~L})$ & $3.30 \pm 0.70$ & $3.42 \pm 0.88$ & $3.24 \pm 0.71$ & 0.425 & 0.306 \\
\hline FVC (L) & $4.05 \pm 0.82$ & $4.15 \pm 1.02$ & $3.94 \pm 0.84$ & 0.428 & 0.066 \\
\hline FEF25-75 (L/sn) & $3.20 \pm 1.13$ & $3.41 \pm 1.28$ & $3.27 \pm 1.19$ & 0.667 & 0.971 \\
\hline $\mathrm{FEV}_{1} / \mathrm{FVC}$ & $81.48 \pm 7.41$ & $82.49 \pm 7.68$ & $82.98 \pm 6.53$ & 0.556 & 0.129 \\
\hline $\mathrm{FEV}_{1} \%$ & $101.02 \pm 12.94$ & $100.13 \pm 13.72$ & $99.05 \pm 15.13$ & 0.765 & 0.665 \\
\hline FVC\% & $105.65 \pm 15.24$ & $101.31 \pm 12.57$ & $100.54 \pm 14.79$ & 0.150 & 0.314 \\
\hline FEF $25-75 \%$ & $91.59 \pm 19.93$ & $94.15 \pm 27$ & $94.29 \pm 28.08$ & 0.939 & 0.965 \\
\hline $\mathrm{FEV}_{1} / \mathrm{FVC} \%$ & $102.41 \pm 10.16$ & $104.95 \pm 11.27$ & $106.05 \pm 11.26$ & 0.229 & 0.597 \\
\hline
\end{tabular}

BMI: Body mass index; FEF25-75: forced expiratory flow between $25 \%$ and $75 \%$ of FVC; FEV : forced expiratory volume in 1 s; FVC: forced vital capacity; PFTs: pulmonary function tests 


\begin{tabular}{|c|c|c|c|c|}
\hline Sex (male) & $54(58.7)$ & $39(50)$ & 0.256 & - \\
\hline $\mathrm{FEV}_{1}(\mathrm{~L})$ & $3.46 \pm 0.78$ & $3.16 \pm 0.74$ & 0.011 & 0.498 \\
\hline FEF25-75 (L/sn) & $3.45 \pm 1.25$ & $3.13 \pm 1.13$ & 0.087 & 0.777 \\
\hline $\mathrm{FEV}_{1} / \mathrm{FVC}$ & $82.26 \pm 7.7$ & $82.56 \pm 6.55$ & 0.785 & 0.236 \\
\hline $\mathrm{FEV}_{1} \%$ & $101.28 \pm 12.81$ & $98.42 \pm 15.23$ & 0.185 & 0.265 \\
\hline FVC\% & $103.54 \pm 13.74$ & $100.62 \pm 14.74$ & 0.182 & 0.147 \\
\hline
\end{tabular}

Table 4. The comparisons of pulmonary functions and other characteristics between BFP Groups

\begin{tabular}{|c|c|c|c|c|}
\hline PFTs & $\begin{array}{c}\text { Ideal* BFP } \\
\mathrm{n}=71^{\#}\end{array}$ & $\begin{array}{l}\text { High* BFP } \\
n=99^{\# \#}\end{array}$ & $\begin{array}{l}\text { Unadjusted } \\
\text { p values }\end{array}$ & $\begin{array}{l}\text { Age- and gender } \\
\text {-adjusted p values }\end{array}$ \\
\hline Age & $36.45 \pm 9.31$ & $42.89 \pm 10.8$ & $<0.001$ & - \\
\hline Sex (male) & $38(53.5)$ & $55(55.6)$ & 0.739 & - \\
\hline $\mathrm{FEV}_{1}(\mathrm{~L})$ & $3.49 \pm 0.76$ & $3.2 \pm 0.76$ & 0.015 & 0.135 \\
\hline FVC (L) & $4.19 \pm 0.9$ & $3.94 \pm 0.89$ & 0.072 & 0.346 \\
\hline FEF25-75 (L/sn) & $3.52 \pm 1.2$ & $3.15 \pm 1.19$ & 0.047 & 0.317 \\
\hline $\mathrm{FEV}_{1} / \mathrm{FVC}$ & $83.32 \pm 6.71$ & $81.74 \pm 7.46$ & 0.156 & 0.619 \\
\hline $\mathrm{FEV}_{1} \%$ & $102.58 \pm 12.12$ & $98.1 \pm 14.99$ & 0.039 & 0.046 \\
\hline FVC\% & $103.75 \pm 13.1$ & $101.09 \pm 14.97$ & 0.231 & 0.263 \\
\hline FEF $25-75 \%$ & $99.59 \pm 22.55$ & $89.14 \pm 26.84$ & 0.008 & 0.006 \\
\hline $\mathrm{FEV}_{1} / \mathrm{FVC} \%$ & $105.48 \pm 10.46$ & $104.09 \pm 11.4$ & 0.419 & 0.221 \\
\hline
\end{tabular}

BFP: Body fat percentage; FEF25-75: Forced expiratory flow between $25 \%$ and $75 \%$ of FVC; FEV : Forced expiratory volume in 1 second; FVC: Forced vital capacity; PFTs: Pulmonary function tests

\#: Man <\%28.8 and woman <\%33.4; \#\#: Man $\geq \% 28.8$ and woman $\geq \% 33.4$ (Body Fat Mass, percentage)

*According to $95 \%$ percentile values in the normal reference range

fat-free mass (FFM) and PFTs). The continuous data were presented as the mean \pm standard deviation. A p-value of $<0.05$ was considered significant. Analyses were performed using a commercial software (IBM SPSS Statistics, Version 23.0.; IBM Corp., New York, USA).

\section{RESULTS}

A total of 170 patients including 93 males (mean age: $41.97 \pm 10$ years) and 77 females (mean age: $38.06 \pm 10$ years) participated in the study. The general characteristics of the patients are given in Table 1.

When patients were divided into three main groups based on BMI values, there was statistically significant difference among normal, overweight, and obese groups in terms of age $(p<0.001)$ and gen$\operatorname{der}(p<0.001)$. There was no statistically significant difference among groups in terms of smoking status $(p=0.939)$. There was no statistically difference between groups in terms of pulmonary function parameters according to both unadjusted and age- and gender-adjusted tests (Table 2).

When patients were divided into two groups based on BFM, there was statistically significant difference between ideal and high BFM groups in terms of age $(p=0.003)$. There was no statistically significant difference between groups in terms of gender $(p=0.256)$. There was statistically difference between groups in terms of FEV ${ }_{1}$ and FVC ( $p=0.011$ and $p=0.011$ respectively) according to unadjusted tests, but there was no statistically difference was found between groups in terms of FEV 1 and FVC and other pulmonary function tests according to unadjusted and age- and gender-adjusted tests (Table 3 ). 
When patients were divided into two groups based on BFP, there was statistically significant difference between ideal and high fat percentage groups in terms of age $(p<0.001)$. There was no statistically significant difference between groups in terms of gender $(p=0.739)$. There was statistically difference between the groups in terms of $\mathrm{FEV}_{1}$ and FEF25-75\% ( $\mathrm{p}=0.015$ and $=0.047$, respectively) according to unadjusted tests. There was statistically difference between groups in terms of FEV $\%$ and FEF25-75\% according to both unadjusted ( $p=0.039$ and $p=0.008$, respectively) and adjusted $(p=0.046$ and $p=0.006$, respectively) tests (Table 4 ).

In the anthropometric assessment of the patients, in the male patients, the $\mathrm{FEV}_{1} \%$ value was negatively correlated with the waist circumference $(r=-0.213, p=0.040)$. In female patients, the WHR was positively correlated with $\mathrm{FEV}_{1} / \mathrm{FVC}(\mathrm{r}=0.488, \mathrm{p}<0.001), \mathrm{FEV}_{1} / \mathrm{FVC} \%$ $(r=0.368, p=0.001)$, whereas it was negatively correlated with $\mathrm{FEV}_{1} \%$ $(r=-0.240, p=0.035)$ values.

\section{DISCUSSION}

Pulmonary function test sare widely used in the evaluation of respiratory status of the individuals and in the monitoring treatment of patients with lung diseases. In addition, it has become a routine part of general health examinations and public health screening. PFT results are interpreted according to the ATS guidelines proposed in the normal range of reference values. Since body weight has a slight contribution to the pulmonary function parameter, the reference values of $\mathrm{FEV}_{1}$ and FVC are determined by age and height of the patients (10). Lungs, chest wall, and respiratory muscles play a common role in the determination of pulmonary functions. Therefore, even though lungs are completely normal, changes in pulmonary function can be expected due to the effect of obesity on the chest wall and diaphragm. It has been reported that obesity is associated with decreased chest wall compliance, reduced lung volume, impaired airway function, breast skeletal muscle dysfunction, and arterial hypoxemia (11).

In this case, BFP and BFD may be a better indicator in the evaluation of pulmonary functions of obese individuals, whose prevalenaceis increasing around the globe, compared to the evaluations performed based on BMI, which is determined by only weight and height. In our study, although no relationship was found between BMI increase and pulmonary functions, significant correlation was found between pulmonary functions and BFP. In male patients, there was correlation between pulmonary functions and waist circumference, whereas there was also correlation between WHR and pulmonary functions of female patients.

In the studies conducted in obese people, it has been suggested that the decrease in the chest wall compliance may be caused by adipose tissue around the abdomen (12). The effects of obesity was determined as reduction in functional residual capacity and expiratory reserve volume and increase in residual volume (13).

In most studies, no relationship was found among $\mathrm{FEV}_{1}, \mathrm{FVC}_{1} \mathrm{FEV}_{1} /$ FVC ratio, and FEF25-75\% values, which are the basic parameters of obstructive and restrictive lung disease, and BMI (14-17). In our study, no relationship was found between $\mathrm{BMI}$ and these parameters. This can be explained by the fact that BMI is not able to show body adiposity and intrathoracic-subpleural fat.

In a few studies, the amount and distribution of body fat has been reported to be associated with pulmonary functions. Especially in severely obese people, a negative correlation was found between BFMand lung functions, whereas FFM positively correlated with pulmo- nary functions $(18,19)$. In adults, a negative correlation was observed between upper body lipoidosis and respiratory functions (20). In addition, in the PFT comparisons performed based on BFD type, the val-

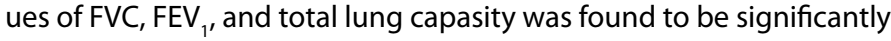
lower in the patients with a higher WHR (15). In our study, a significant correlation was found between these parameters and BFP and other anthropometric parameters. This significance can be explained by the fact that the fat mass, which increases the load on chest wall, stored in the abdominal cavity probably prevents the descent of the diaphragm and causes restrictive-type respiratory disorders.

In the study by Lorenzo et al. (19), it has been reported that there was an improvement in airway limitation with a reduction in total body fat after following a diet and the largest improvement was seen in the FEF $25-75 \%$ value. In our study, the FEF $25-75 \%$ value was found to be correlated with BFP. This case can be explained by fact that the smaller airways are more affected than the large airways by the visceral adiposity.

The strength of our study is the detailed examination of all the patients and exclusion of those with comorbid diseases. In addition, to the best of our knowledge, this is the first study in Turkey using the bio-impedance method.

The limitation of our study is conducting it with a relatively small number of patients in a single center. We believe that it would be more effective to perform the research with a large number of patients in which simple anthropometric parameters will be measured to determine the reference values of PFTs for obese people.

\section{CONCLUSION}

Beause it has been concluded that the widely used BMI in the obesity classification can not distinguish BFD, it is insufficient for evaluating the pulmonary functions; therefore, determining the body composition is important in the evaluation of obese individuals.

Ethics Committee Approval: Ethics committee approval was received for this study from the ethics committee of Sakarya University Medical Faculty.

Informed Consent: Written informed consent was obtained from all the patients who participated in this study.

Peer-review: Externally peer-reviewed.

Author Contributions: Concept - D.G., Y.A., R.A.; Design - D.G., Y.A., R.A.; Supervision - D.G., Y.A., R.A.; Resources - D.G., Y.A.; Materials - D.G., Y.A., R.A.; Data Collection and/or Processing - D.G., Y.A., R.A. Analysis and/or Interpretation - D.G., Y.A., Ü.E.; Literature Search - D.G., Y.A.; Writing Manuscript - Y.A., D.G.; Other - Ü.E.

Conflict of Interest: No conflict of interest was declared by the authors.

Financial Disclosure: The authors declared that this study has received financial support from Sakarya University, Scientific Research Projects Unit (Project No:2012-11-00-002).

\section{REFERENCES}

1. Vanltallie TB. Prevalence of obesity. Endocrinol Metab Clin North Am 1996; 25: 887-905. [CrossRef]

2. Çolak Y, Marott JL, Vestbo J, Lange P. Overweight and obesity may lead to under-diagnosis of airflow limitation: findings from the Copenhagen City Heart Study. COPD 2015; 12: 5-13. [CrossRef]

3. Physical status: the use and interpretation of anthropometry. Report of a WHO Expert Committee. World Health Organ Tech Rep Ser 1995; 854: 1-452.

4. Okorodudu DO, Jumean MF, Montori VM, Romero-Corral A, Somers VK, Erwin PJ, et al. Diagnostic performance of body mass index to identify 
obesity as defined by body adiposity: a systematic review and meta-analysis. Int J Obes (Lond) 2010; 34: 791-9. [CrossRef]

5. Jackson AS, Stanforth PR, Gagnon J, Rankinen T, Leon AS, Rao DC, et al. The effect of sex, age and race on estimating percentage body fat from body mass index: The Heritage Family Study. Int J Obes Relat Metab Disord 2002; 26: 789-96.

6. Thijs W, Alizadeh Dehnavi R, Hiemstra PS, de Roos A, Melissant CF, Janssen $\mathrm{K}$, et al. Association of pulmonary function measurements and visceral fat in men with metabolic syndrome. Respir Med 2014; 108: 351-7. [CrossRef]

7. Pichard C, Kyle UG, Bracco D, Slosman DO, Morabia A, Schutz Y. Reference values of fat-free and fat masses by bioelectrical impedance analysis in 3393 healthy subjects. Nutrition 2000; 16: 245-54. [CrossRef]

8. World Health Organisation. Measuring obesity: classification and description of anthropometric data. Copenhagen: WHO, 1989 (Nutr UD, EUR/ICP/NUT 125).

9. Pellegrino R, Viegi G, Brusasco V, Crapo RO, Burgos F, Casaburi R, et al. Interpretative strategies for lung function tests. Eur Respir J 2005; 26 : 948-68. [CrossRef]

10. American Thoracic Society. Lung function testing: selection of reference values and interpretative strategies. Am Rev Resp Dis 1991; 144: 1202-18. [CrossRef]

11. Ray CS, Sue DY, Bray G, Hansen JE, Wasserman K. Effects of obesity on respiratory function. Am Rev Respir Dis 1983; 128: 501-6. [CrossRef]
12. Maiolo C, Mohamed El, Carbonelli MG. Body composition and respiratory function. Acta Diabetol 2003; 40 (Suppl 1): S32-8. [CrossRef]

13. Jones RL, Nzekwu MM. The effects of body mass index on lung volumes. Chest 2006; 130: 827-33. [CrossRef]

14. Ghobain MA. The effect of obesity on spirometry tests among healthy non-smoking adults. BMC Pulm Med 2012; 12: 10. [CrossRef]

15. Collins LC, Hoberty PD, Walker JF, Fletcher EC, Peiris AN. The effect of body fat distribution on pulmonary function tests. Chest 1995; 107: 1298-302. [CrossRef]

16. Costa D, Barbalho MC, Miguel GP, Forti EM, Azevedo JL. The impact of obesity on pulmonary function in adult women. Clinics (Sao Paulo) 2008; 63: 719-24. [CrossRef]

17. Tomruk S, İbrahimoğlu F, Sezer N, Köseoğlu BF, Tekin D. The Effects of Body Fat Distribution on Pulmonary Function and Respiratory Muscle Strength in Obese Individuals. Turk J Phys Med Rehab 2006; 52: 15-8.

18. Lazarus R, Sparrow D, Weiss ST. Effects of obesity and fat distribution on ventilatory function: the normative aging study. Chest 1997; 111: 891-8. [CrossRef]

19. De Lorenzo A, Maiolo C, Mohamed El, Andreoli A, Petrone-De Luca P, Rossi P. Body composition analysis and changes in airways function in obese adults after hypocaloric diet. Chest 2001; 119: 1409-15. [CrossRef]

20. Harik-Khan RI, Wise RA, Fleg JL. The effect of gender on the relationship between body fat distribution and lung function. J Clin Epidemiol 2001; 54: 399-406. [CrossRef] 